https://helda.helsinki.fi

\title{
Organic Aerosols and the Origin of Life : An Hypothesis
}

\section{Donaldson, D.J.}

Springer Science+Business Media B.V.

2004

Donaldson, D.J., Tervahattu, H. and Tuck, A.F. 2004. Organic Aerosols and the Origin of pÿLife: An Hypothesis. Origins of Life and Evolution of the Biosphere 34: 5767.

http://hdl.handle.net/1975/240

Downloaded from Helda, University of Helsinki institutional repository.

This is an electronic reprint of the original article.

This reprint may differ from the original in pagination and typographic detail.

Please cite the original version. 


\title{
ORGANIC AEROSOLS AND THE ORIGIN OF LIFE: AN HYPOTHESIS
}

\author{
D. J. DONALDSON ${ }^{1}, \mathrm{H}$. TERVAHATTU ${ }^{2}$, A. F. TUCK ${ }^{3 *}$ and V. VAIDA ${ }^{4}$ \\ ${ }^{1}$ Department of Chemistry, University of Toronto, Toronto, Canada; ${ }^{2}$ Department of Limnology and \\ Environmental Protection, University of Helsinki, Helsinki, Finland; ${ }^{3}$ Meteorological Chemistry \\ Program, National Oceanic and Atmospheric Administration, Aeronomy Laboratory, 325 \\ Broadway, Boulder, CO 80305-3328, U.S.A.; ${ }^{4}$ Department of Chemistry and Biochemistry, \\ University of Colorado, Boulder, Colorado, U.S.A. \\ (*author for correspondence, e-mail: tuck@al.noaa.gov)
}

(Received 20 October 2002; accepted in revised form 19 March 2003)

\begin{abstract}
Recent experimental work has verified the prediction that marine aerosols could have an exterior film of amphiphiles; palmitic, stearic and oleic acids were predominant. Thermodynamic analysis has revealed that such aerosols are energetically capable of asymmetric division. In a prebiotic terrestrial environment, one of the products of such aerosol fission would have been bacterially sized (microns), the other would have been virally sized (tens of nanometers). Plausible avenues for chemical differentiation between the two particles are discussed, and the probabilities for the transition from geochemistry to biochemistry updated in light of recent palaeo fossil studies.
\end{abstract}

Keywords: marine aerosols, fission, bacteria, virus

\section{Introduction}

This paper reviews the recent development of the idea that inverted micelle atmospheric aerosols could have been the site on the Archaean Earth, set by geophysics, at which geochemistry was transformed into biochemistry. The idea itself is now buttressed by observations in the contemporary atmosphere (Murphy et al., 1998; Tervahattu et al., 2002a, 2002b), and can be traced back through earlier suggestions by Goldacre (1958), Shah (1970) and Lerman (1986, 1992, 1994, 1996). Dobson et al. (2000) gave an equation (Kasten 1968) expressing how the balance between gravitation and aerodynamic drag determines the size of aerosol particles having an appreciable residence time in the atmosphere, and Donaldson et al. (2001) showed thermodynamically how the free energetics of the collapse of an exterior film of amphiphilic molecules on an aerosol could lead to fission, a process not possible for a homogeneous uncoated liquid aerosol. The fission must be asymmetric; for a prebiotic Earth atmosphere with one bar surface pressure, the larger daughter particle is bacterially-sized while the smaller one is virally-sized (Donaldson et al., 2002). The fission must be asymmetric because it is enabled by the free energy change of a compressible amphiphilic film, which is small compared to the free energy (surface tension) of the spherical parent droplet (Donaldson et al., 2001). Using the available literature we attempt to estimate the number of opportunities which 
would have arisen for a continually regenerated set of aerosols to be transformed into a self-ordering, self-replicating population (Dyson, 1999; Donaldson et al., 2002). The result implies that initially successful evolutions ended predominantly in failure before an enduring living population emerged. Also possible is the coevolution of bacteria and viruses, with chemical as well as physical differentiation emerging via the characteristics of amphiphilic films on polar solutions. It may be difficult to define a sharp transition from a geochemical population to a biochemical population in such circumstances.

\section{Recent Observational Evidence}

Very recently, for the first time direct evidence has emerged of an organic film on the exterior of marine aerosols (Tervahattu et al., 2002a), consisting largely of palmitic, oleic and stearic acids (Tervahattu et al., 2002b). A marine aerosol is one produced by bubble-bursting at the sea surface (Mason, 1954; Blanchard, 1964). The evidence may be seen in Figure 1, which demonstrates that the palmitic acid peak $(\mathrm{m} / \mathrm{z}=255)$ decreases with time under gallium ion bombardment, as do the peaks of the other, less abundant fatty acids. Figure 2 demonstrates that after enough time has elapsed, the fatty acid peaks have decreased by large fractions and chlorine peaks $(\mathrm{m} / \mathrm{z}=35$ and 37$)$ have increased by large fractions, demonstrating that the fatty acids are on the exterior of a sea salt core. This observation confirms the hypothesis of Ellison et al., (1999) that such would be the structure of marine aerosols, and which led to the connection to the origin of life (Dobson et al., 2000). In the present biotic atmosphere, these fatty acids come from the decay of lipids (Sicre et al., 1990); we examine the supply of fatty acid monomers in the prebiotic era in Section 3 below.

Laboratory work has shown recently that even small organic molecules tend to concentrate at the water-air interface (Donaldson and Anderson, 1999), and that the presence of salts in the water can lead to large increases in the surface concentration of even the shorter amphiphiles; Demou and Donaldson (2002) observed a $\sim 50 \%$ increase in the surface concentration of hexanoic acid in high ionic strength solutions compared to pure water. This basic molecular mechanism, the 'salting out' effect, should make itself felt on scales as large as the entire ocean surface and as small as the daughter particles produced by asymmetric aerosol fission, see Section 4.

\section{Prebiotic Supply of Monomers}

While the relatively facile prebiotic supply of amino acid monomers for polypeptides and proteins has been investigated and reviewed (Miller, 1998), and the more difficult supply of purine and pyrimidine monomers for nucleotides has been 


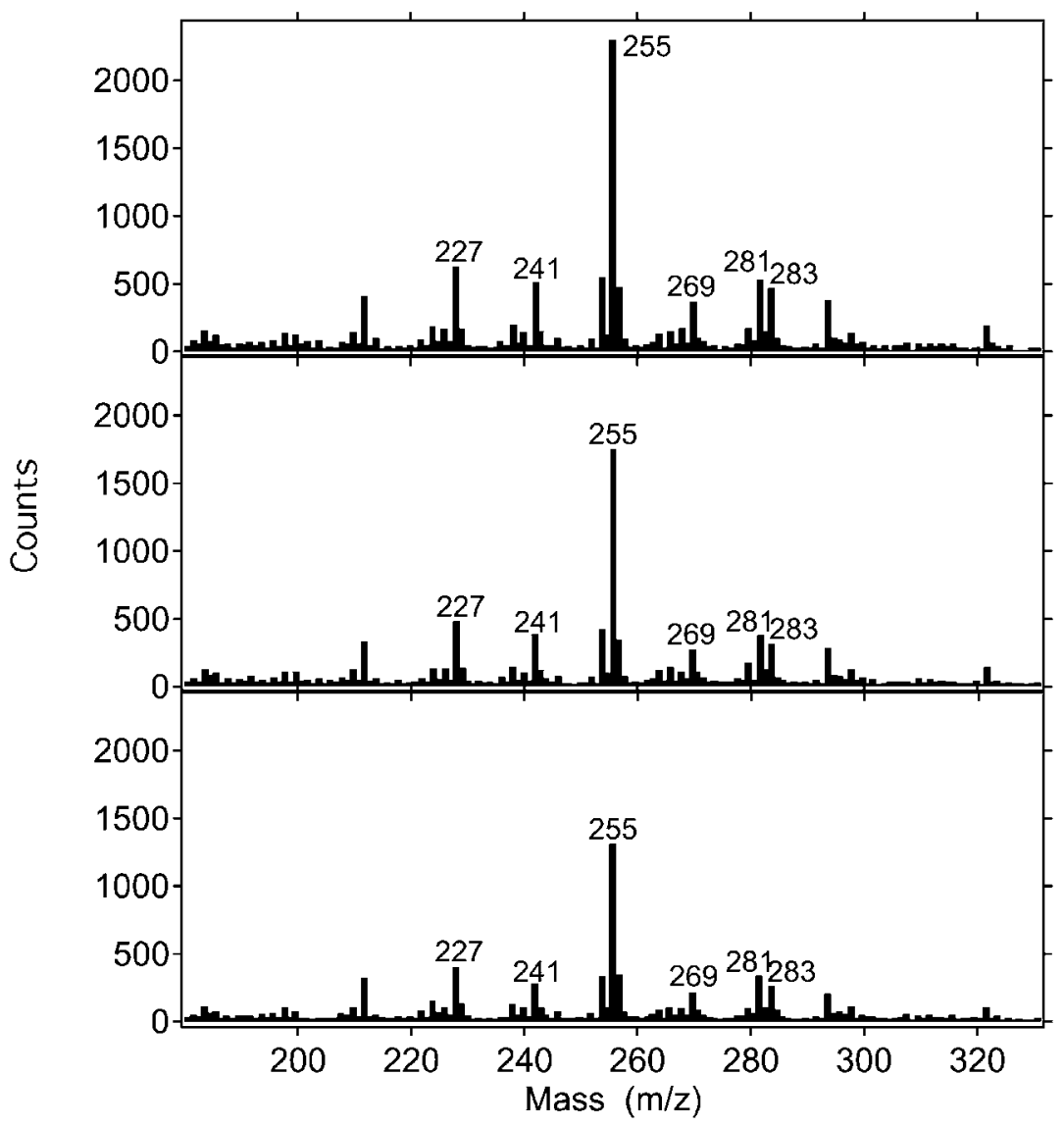

Figure 1. Successive negative ion TOF-SIMS spectra, each of $120 \mathrm{~s}$ duration, of the same marine aerosol; palmitic acid is the most abundant. During the gallium ion bombardment, the $\mathrm{m} / \mathrm{z}$ peaks characteristic of $\mathrm{C}_{14}-\mathrm{C}_{18}$ fatty acids decline in intensity. The results show that the outer parts of the aerosol are composed of these fatty acids (Tervahattu et al., 2002b).

successfully pursued from something as simple as a solution of ammonium cyanide (e.g., Oró, 1961; Miyakawa et al., 2002), there is no such underpinning for long chain $n$-alkanoic acids. It is however known that a wide selection of alkanes is produced by the action of water on iron carbide (Chamberlin and Chamberlin, 1908), with a preponderance of $n$-isomers in some circumstances (Marquez et al., 1996). There was undoubtedly water vapour in the prebiotic atmosphere, along with ultraviolet photons to shorter wavelengths than at present, consistent with the then major absorbers $-\mathrm{CO}_{2}$ (174 nm cut-off) and $\mathrm{H}_{2} \mathrm{O}$ (185 nm cut-off) - compared with $\mathrm{O}_{3}$ (300 nm cut-off) now. The presence of the $\mathrm{OH}$ radical was thus assured, and it would react with alkanes and alkenes both in the gas phase (Atkinson, 1997) and on surface films (Ellison et al., 1999; Bertram et al., 2001). Tuck (2002) has used literature data on alkyl recombination rates to argue that chain lengthening 

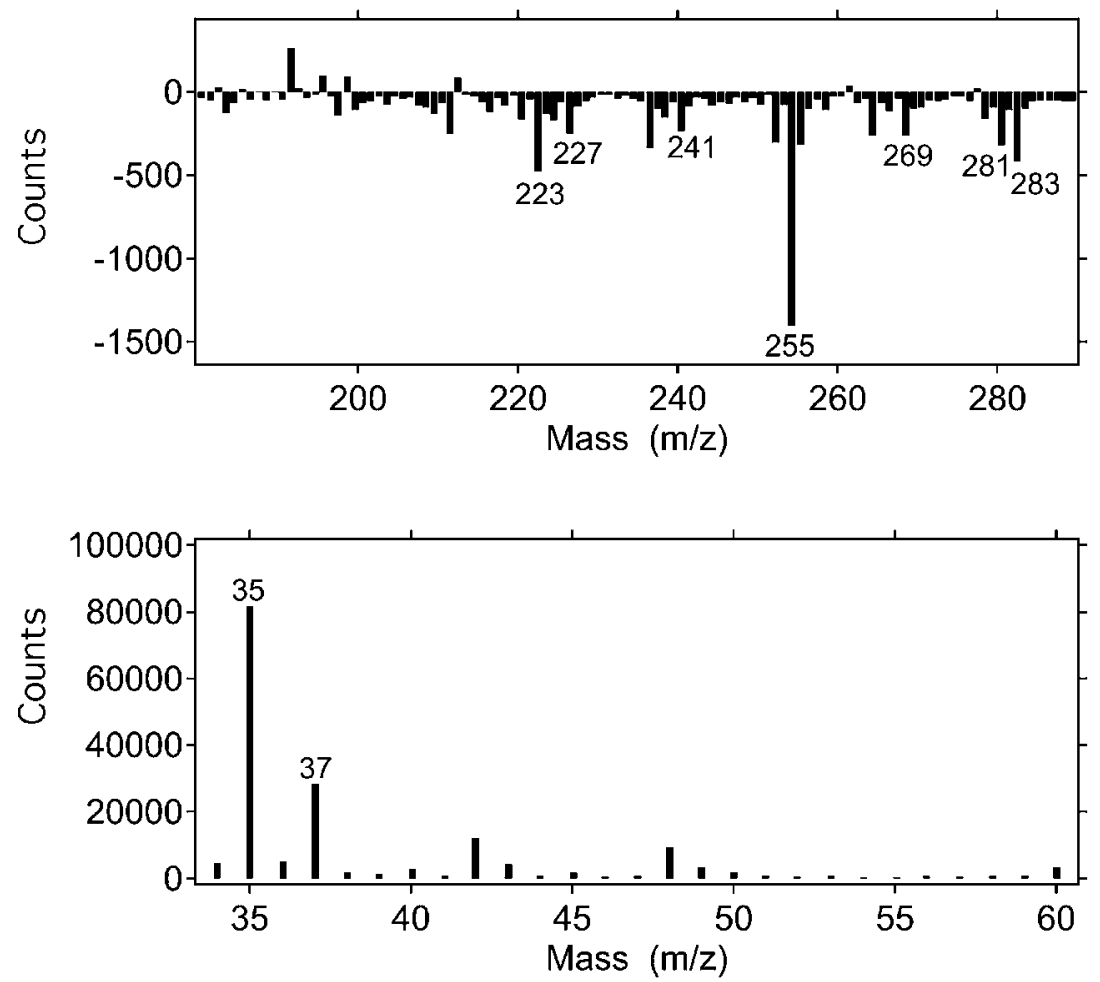

Figure 2. The effect of sputtering for the TOF-SIMS peaks of chlorine $(\mathrm{m} / \mathrm{z}=35$ and 37$)$ and of palmic acid $(\mathrm{m} / \mathrm{z}=255)$. The vertical bars show the signs and intensities of the changes induced by sputtering. The peaks from fatty acids on the surface decrease, accompanied by an increase of the peaks from chlorine in the interior (Tervahattu et al., 2002b).

in hydrocarbons in the anaerobic prebiotic atmosphere would have resulted from gas phase reaction $\mathrm{OH}$ with methane, with further oxidation to alcohols, aldehydes and acids. A kinetic preference to form $n$-isomers of alkyl radicals exists, but there would still have been many branched isomers present. It was further argued, based on the literature, that branched isomers of amphiphiles, for example alkanoic acids, would be ejected preferentially from surface films under compression on aerosols, leaving $n$-isomers in the film. It is also known that carboxylic acids in Langmuir films polymerize on exposure to ultraviolet radiation (Peltonen et al., 1993). In principle, there appears to be no insuperable difficulty in the supply of $n$-alkanoic acids, particularly in the $\mathrm{C}_{12}-\mathrm{C}_{18}$ range found in marine aerosols, or of amino acids, purines and pyrimidines. This is particularly true in view of the composition of meteorites (e.g. Cronin, 1998), and of production at the sea floor from thermal vents (e.g. Simoneit, 1995; Cody et al., 2000). Self-assembly of prebiotic amphiphiles has been argued (Deamer, 1997). 


\section{Thermodynamics of Aerosol Fission}

It has been shown recently (Donaldson et al., 2001), by thermodynamic analysis of the free energetics of the compression and collapse of amphiphilic films, that an atmospheric aerosol can divide, provided it has substantial coverage by such a surfactant film. This is a new result; for a homogeneous liquid aerosol it is not possible, because the surface tension (free energy) of such a spherical particle already has its minimum value; simple geometry thus allows coagulation but not division, since the surface area of a sphere of radius $r$ is proportional to $3 / r$. With an outer organic film, fission is possible, but it must be asymmetric; putting typical numbers in the equations reveal that for an Earth atmosphere of one bar surface pressure, the larger daughter particle is bacterially sized, while the smaller one is virally sized. Further explanation may be found in Donaldson et al. (2001) and Donaldson et al. (2002). It is of course true that thermodynamic analysis of a simple system with only one amphiphilic species can only show that fission is possible for an idealized aerosol particle; the kinetics of how it would happen for a film of mixed composition, possibly with rafts or islands of differing molecules, in a chemically heterogeneous system like the prebiotic atmosphere and ocean, is a more difficult mechanism to characterize.

If the asymmetric fission of aerosols with organic casings is accepted, some interesting implications are possible. One is that bacteria and viruses are of equal antiquity, with an inextricably entwined evolution. There may have been as many as 1500 million years to transform geophysical and geochemical entities such as the asymmetrically-sized daughters of aerosol fission into biochemical and biological entities such as bacteria and viruses, see Section 6 below. Another implication is that chemical differentiation is possible between the larger and smaller daughters; again the argument is a thermodynamic one addressing possibility, not a kinetic one describing realization (Donaldson et al., 2002). The results of Razumovsky and Damodaran (1999) showed a correlation between surface activity and flexibility within a selection of proteins; the flexible ones more easily unfolded and had high surface activities, while the ones which readily became globular had very little surface activity, i.e. no ability to lower surface tension at an air-water interface. Thus two sorts of chemical differentiation are possible upon fission: one will tend to put globular proteins in the bulk core of the particles and the more flexible, unfolded ones in the outer film along with carboxylic acids. The second one will tend to differentially partition the most flexible proteins of all to the surface of the smaller particle as the film divides, since this would minimize the total free energy. It is possible that there could be differentiation between the two cores, with the molecules which fill space most efficiently occupying the smaller daughter's bulk phase, but this possibility will need examination in kinetic experiments. This basic physico-chemical mechanism would ensure both some seclusion for separate chemical evolution of peptides and oligonucleotides, and intermittent communication and mixing via coagulation of inverted micelle aerosols in the atmosphere and 
of their vesicular successors in the ocean. The considerations underlying the domain model of protein in cellular lipid bilayers (Singer and Nicholson, 1972), and the formation of rafts in membrane monolayers (Dietrich et al., 2001) will come into play, as will the more complicated topologies possible in bilayers (Lipowsky, 1991).

\section{Laboratory Perspectives}

There is little laboratory work on the specific aspects of surface films of amphiphiles at the air-water interface in the context discussed here, either on aerosols or bulk planar interfaces. One significant past study was that of StällbergStenhagen and Stenhagen (1945), which showed that when the $\mathrm{R}_{1}: \mathrm{R}_{2}$ ratio was systematically varied from $1: 14$ to $7: 8$ in $\mathrm{R}_{1} \mathrm{R}_{2} \mathrm{HCCOOH}$, the linear chain $n$ isomers packed better than the branched $s$ - and $t$-isomers, minimizing surface tension and hence free energy. This could have been an important naturally selective mechanism resulting in a preference for $n$-alkanoic acids in the prebiotic environment, and hence in amphiphilic films at air-water interfaces on the sea surface and aerosols, provided that the curvature of the aerosol is not pronounced, a condition holding for the sizes we are discussing. In very small vesicles, it is possible that branched chain isomers could form the more stable film. The possibility that branched alkane isomers are preferentially ejected from such films upon compression receives theoretical support from the molecular dynamics calculations of Gao et al. (1997).

Laboratory gas kinetic studies have shown that higher molecular weight alkanes react faster with $\mathrm{OH}$ than lighter ones, and that the $n$-isomers react somewhat faster than their branched homologues (Atkinson, 1997). This will result, via alkyl radical-recombination reactions, in the lengthening of the alkanes in an atmosphere in which only methane was present initially (Tuck, 2002). Disproportionation and isomerization of sec - and tert - alkyl radicals (Kerr and Trotman-Dickinson, 1961; Leathard and Purnell, 1970) will lead kinetically to a higher fraction of $n$-isomers than would be obtained at thermodynamic equilibrium. However, it is likely that the preferential ejection of branched isomers from films described in the previous paragraph would be necessary to supplement this mechanism.

The formation of diamino and dicarboxylic amino acids in prebiotic simulation experiments (Miller, 1998) means that branching is possible during polymerization to peptides. Again, some mechanism favoring linear chain isomers is required. It may be that the mechanism proposed by Gee and Rideal (1936), who said that one-at-a-time addition of monomers to a growing polymer aligned in a monolayer of $\beta$-elaeosterin could explain their observations made as the film dried, is of a general form which could produce unbranched chains.

It is perhaps surprisingly difficult to locate reports of the polymerization of amino acids to peptides under exposure to ultraviolet light. Haselmann and Laus- 
triat (1973) reported the production, in low yield, of the pigment melanin from the amino acid tyrosine under $254 \mathrm{~nm}$ irradiation. This is potentially important because it offers the possibility of a UV shield on the prebiotic planet, before the evolution of an aerobic atmosphere and its concomitant ozone layer.

\section{The Geochemical and Geophysical Environment for Prebiotic Aerosols}

The rotation of the Earth about a tilted axis would have ensured winds, ocean whitecaps and hence aerosols. The aerosol cycles 'must have been' occurring (Lerman, 1996).

In Section 2 we have outlined how a supply of monomeric species for generation of biopolymers could be maintained, but without considering the photodissociation of any oligopeptides or oligonucleotide products by ultraviolet radiation from the sun in the absence of an ozone layer. While there is of course considerable uncertainty about the composition of the prebiotic atmosphere, we will suppose that it contained $\mathrm{N}_{2}, \mathrm{CO}_{2}, \mathrm{H}_{2} \mathrm{O}$ and some lesser amounts of methane and ammonia. Such an atmosphere will, depending on abundances and vertical distributions, have its short wave cut-off set by $\mathrm{CO}_{2}$ at $174 \mathrm{~nm}$ or by $\mathrm{H}_{2} \mathrm{O}$ at $185 \mathrm{~nm}$. Since ammonia and amino acids absorb at longer wavelengths, up to $220 \mathrm{~nm}$ and into the near UV and visible for amino acids with conjugated double bonds and/or aromatic rings in their side chains, the effects of photolysis have to be considered.

The present UV transmission of the atmosphere is largely determined by oxygen and ozone. Molecular oxygen photodissociates to produce oxygen atoms at wavelengths less than $242 \mathrm{~nm}$; the oxygen atoms recombine with other $\mathrm{O}_{2}$ molecules to produce ozone. Although ozone photodissociates across the near UV and visible to about $1100 \mathrm{~nm}$, there is a dynamic balance between photochemical and transport processes to produce a layer of ozone, centred in number density terms at about $24 \mathrm{~km}$ altitude in the stratosphere. Above this maximum, there are relatively many actinic photons and relatively few absorbing molecules; below it there are relatively many molecules and relatively few photons; at the maximum, there is simultaneous occurrence of photon and molecule densities sufficient to produce the $\mathrm{O}_{3}$ layer maximum (Goody and Walker, 1972; Tuck, 2002). In the anaerobic prebiotic atmosphere, this general mechanism would have applied to any functionalized amino acids and polypeptides, and would have been located in the atmosphere for those molecules with a high enough vapour pressure, and at the sea surface for those which would be liquid at the temperatures of the ocean-air interface. This process implies that over time there would be a substantial accumulation of reactive forms of carbon, hydrogen, oxygen and nitrogen in species with low vapour pressures and absorption bands at progressively longer wavelengths. This accumulation would have occurred at the expense of the $\mathrm{CH}_{4}, \mathrm{CO}_{2}, \mathrm{H}_{2} \mathrm{O}$ and $\mathrm{NH}_{3}$ inventories. 
Dobson et al. (2000) pointed out that the very large, continually recycled aerosol populations would have been potentially versatile chemical reactors in the prebiotic atmosphere. A wide range of radiation, temperature and humidity fields would have been sampled by aerosols transported by the general circulation; in the present atmosphere temperature ranges from $-90^{\circ} \mathrm{C}$ to $+40^{\circ} \mathrm{C}$ and relative humidity ranges from $0 \%$ to $100 \%$. The solar radiation spectrum can vary from being virtually unattenuated from $175 \mathrm{~nm}$ to $1000 \mathrm{~nm}$ in the upper stratosphere, where the residence time is years, to having 6 months of darkness at the winter poles and continuous visible light for months at the summer pole. There would have been a great deal of prebiotic chemical variation in the aerosols upon which natural selection could have acted. It could also have had a very long time in which to act: it would have been 500 million years after the end of the late heavy meteor bombardment if Schopf's (2002) dating (3.5 billion years) of the oldest fossil bacteria is accepted, but if Brasier et al.'s (2002) criticism is accepted then the first bacterial appearance in the fossil record could have been as late as 2.5 billion years ago. This would leave a span as long as 1.5 billion years for geochemistry to become biochemistry. Accepting Dyson's $(1985,1999)$ estimates for the frequency of occurrence of one self-ordering event in a population of autocatalytic molecules and using aerosol number densities typical of the present atmosphere, Donaldson et al. (2002) estimated $\sim 10^{31}$ opportunities for a successful living population to emerge, a number which would increase to an upper limit of $\sim 10^{32}$ cycles if the transition was as late as 2.5 billion years ago. Such a large number of chances would seem to imply many initial successes resulting in eventual failure before a successful biochemical population emerged and endured. If the mechanism we have proposed was at work, the natural progression would be of co-evolution of bacteria and viruses, with possible concomitant co-evolution of peptides and nucleic acids.

\section{Experimental Tests}

Perhaps the main justification for proposing aerosols as the prebiotic chemical reactors which effected the transition from geochemistry to biochemistry is that many of the first steps in the mechanisms can be tested experimentally. This is possible because the mechanism is rooted in atmospheric observation, and invokes known physico-chemical principles. Examples are the presence of alkanoic and alkenoic acids as outer films on marine aerosols, the polymerization of carboxylic acids in UV-irradiated films and the preferential ejection of branched isomers of $\mathrm{R}_{1} \mathrm{R}_{2} \mathrm{HCCOOH}$ from Langmuir films. Untested ideas are the polymerization of monomers by condensation reactions in the hydrophobic environment of amphiphilic films, the asymmetric fission of organically coated aerosols into a bacteriallysized and a virally-sized pair of daughters, and the idea that chemical differentiation can occur during such a fissile process. Perhaps more difficult to test is the intuitive suggestion of co-evolution of the predecessors of proteins and nucleic 
acids. It should be possible to test the acquisition of a second lipid layer by aerosols re-entering at the air-water interface.

\section{Summary: Sequence of Events}

What we propose is a sequence of events as follows.

- Photochemical reaction converts atmospheric gases such as $\mathrm{CH}_{4}, \mathrm{NH}_{3}, \mathrm{HCHO}$ into higher molecular weight compounds which accumulate in the atmosphere and, as their size increases and their vapour pressure decreases, at the ocean surface.

- Carboxylic acids are produced by reaction of $\mathrm{OH}$ with hydrocarbons at the air-water interface, especially on aerosols. The n-isomers are selected at this location by preferential ejection of branched isomers from the Langmuir films.

- Amino acids polymerize by one-at-a-time addition of monomers occurring in condensation reactions in the hydrophobic environment of the surface films on the aerosols. Solar UV photons provide the energy.

- Purines and pyrimidines, possibly formed from nitriles experiencing very low temperatures at the poles or at the tropical tropopause, co-evolve with peptides in the coagulating and asymmetrically dividing population of aerosols. The inverted micelle aerosols acquire a second amphiphilic layer upon reentry to the ocean, becoming vesicles. Over geological time, in a period possibly as long as 1.5 billion years continually recycled, numerous and mobile bimodal populations of bacterially and virally sized aerosols and vesicles acquire

the characteristics of life during the estimated $\sim 10^{31}-10^{32}$ opportunities (Donaldson et al., 2002). Such a large number probably implies that there would have been many failures in initially successful populations making the transition from geochemistry to biochemistry before one endured. In view of the posited lengthy co-evolution of bacterially and virally sized populations of particles, the distribution of molecular properties characterizing the transition may prove to be ill-defined, and possibly elusive in the context of laboratory experiment.

\section{References}

Atkinson, R.: 1997, Gas Phase Tropospheric Chemistry of Volatile Organic Compounds: 1. Alkanes and Alkenes J. Phys. Chem. Ref. Data 26, 214-290.

Bertram, A. K., Ivanov, A. V., Hunter, M., Molina, L. T. and Molina, M. J.: 2001, The Reactionprobability of $\mathrm{OH}$ on Organic Surfaces of Tropospheric Interest, J. Phys. Chem. A 105, 94159421.

Blanchard, D. C.: 1964, Sea-to-Air Transport of Surface Active Material, Prog. Oceanog. 1, 71-202. 
Brasier, M. D., Green, O. R., Jephcoat, A. P., Kleppe, A. K., van Kranendonk, M. J., Lindsay, J. F., Steele, A. and Grassineau, N. V.: 2002, Questioning the Evidence for Earth's Oldest Fossils, Nature 416, 76-81.

Chamberlin, T. C. and Chamberlin R. T.: 1908, Early Terrestrial Conditions that may have Favoured Organic Synthesis, Science 28, 897-911.

Cronin, J. R.: 1998, Clues from the Origin of the Solar System: Meteorites, Chapter 6, The Molecular Origins of Life, Cambridge University Press, pp. 119-146.

Deamer, D. W.: 1997, The First Living Systems: A Bioenergetic Perspective, Microbiol. Mol. Biol. Revs. 61, 239-261.

Demou, E. and Donaldson, D. J.: 2002, Adsorption of Atmospheric Gases at the Air-water Interface. 4. The Influence of Salts, J. Phys. Chem. A 106, 982-987.

Dietrich, C., Volovyk, Z. N., Levi, M., Thompson, N. L. and Jacobson, K.: 2001, Partitioning of Thy1, GM1, and Cross-Linked Phospholipid Analogs into Lipid Rafts Reconstituted in Supported Model Membrane Layers, Proc. Nat. Acad. Sci. 98, 10642-10647.

Dobson, C. M., Ellison, G. B., Tuck, A. F. and Vaida, V.: 2000, Atmospheric Aerosols as Prebiotic Chemical Reactors, Proc. Nat. Acad. Sci. 97, 11864-11868.

Donaldson, D. J. and Anderson, D.: 1999, Adsorption of Atmospheric Gases at the Air-Water Interface. 2. $\mathrm{C}_{1}-\mathrm{C}_{4}$ Alcohols, Acids and Acetone, J. Phys. Chem. A 103, 871-876.

Donaldson, D. J., Tuck, A. F. and Vaida, V.: 2001, Spontaneous Fission of Atmospheric Aerosol Particles, Phys. Chem. Chem. Phys. 3, 5270-5273.

Donaldson, D. J., Tuck, A. F. and Vaida, V.: 2002, The Asymmetry of Organic Aerosol Fission and Prebiotic Chemistry, Orig. Life Evol. Biosph. 32, 237-245.

Dyson, F. J.: 1985, 1999, Origins of Life, 1st and 2nd Editions, Cambridge University Press.

Ellison, G. B., Tuck, A. F. and Vaida, V.: 1999, Atmospheric Processing of Organic Aerosols, J. Geophys. Res. 104, 11633-11642.

Gao, J., Luedtke, W. D. and Landman, U.: 1997, Origin of Solvation Forces in Confined Films, J. Phys. Chem. B 101, 4013-4023.

Gee, G. and Rideal, E. K.: 1936, Reactions in Monolayers of Drying Oils. I. The Oxidation of the Maleic Anhydride Compound of $\beta$-Elaeosterin. II. Polymerization of the Oxidized Forms of the Maleic Anhydride Compound of $\beta$-elaeosterin, Proc. Roy. Soc. A 153, 116-128, 129-141.

Goldacre, R. J.: 1958, Surface Films, their Collapse on Compression, the Shapes and Sizes of Cells and the Origin of Life, in J. F. Danielli, K. G. A. Parkhurst and A. C. Riddiford (eds.), Surface Phenomena in Chemistry and Biology, Pergamon Press, pp. 278-298.

Goody, R. M. and Walker, J. C. G.: 1972, Atmospheres, pp. 25-27.

Haselmann, C. and Laustriat, G.: 1973, Photochimie des acides amines aromatiques en solution - I. DL-phenylalanine, DL-tyrosine et L-dopa, Photochem. Photobiol. 17, 275-294.

Kerr, J. A. and Trotman-Dickinson, A. F.: 1961, The Reactions of Alkyl Radicals, in G. Porter (ed.), Progress in Reaction Kinetics 1, Chapter 4, Pergamon Press, pp. 105-128.

Leathard, D. A. and Purnell, J. H.: 1970, Paraffin Pyrolysis, Ann. Rev. Phys. Chem. 21, 197-224.

Lerman, L.: 1986, Potential Role of Bubbles and Droplets in Primordial and Planetary Chemistry: Exploration of the Liquid-Gas Interface as a Reaction Zone for Condensation Processes, Orig. Life Evol. Biosph. 16, 201-202.

Lerman, L.: 1992, The Liquid-Gas Interface as a Reaction Zone for Condensation Processes: Bubbles and Droplets in Primordial and Planetary Chemistry, M.S. Thesis, Stanford University.

Lerman, L.: 1994, The Bubble-Aerosol Droplet Cycle as a Natural Reactor for Prebiotic Organic Chemistry (I), Orig. Life Evol. Biosph. 24, 111-112.

Lerman, L.: 1996, The Bubble-Aerosol-Droplet Cycle: A Prebiotic Geochemical Reactor, Orig. Life Evol. Biosph. 26, 369-370.

Lipowsky, R.: 1991, The Conformation of Membranes, Nature 349, 475-481.

Marquez, C., Lazcano, A., Miller, S. L. and Oro, J.: 1996, Fully Deuterated Aliphatic Hydrocarbons Obtained from Iron Carbide Treated with $\mathrm{DCl}$ and $\mathrm{D}_{2} \mathrm{O}$, Orig. Life Evol. Biosph. 26, 450-451. 
Mason, B. J.: 1954, Bursting of Air Bubbles at the Surface of Sea Water, Nature 174, 470-471.

Miller, S. L.: 1998, The Endogenous Synthesis of Organic Compounds, Chapter 3, The Molecular Origins of Life, Cambridge University Press, pp. 59-85.

Mijakawa, S., Cleaves, H. J. and Miller, S. L.: 2002, The Cold Origin of Life: B. Implications Based on Pyrimidines and Purines Produced from Frozen Ammonium Cyanide Solutions, Orig. Life Evol. Biosph. 32, 209-218.

Murphy, D. M., Thomson, D. S. and Mahoney, M. J.: 1998, In situ Measurements of Organics, Meteoritic Material, Mercury and Other Elements in Aerosols at 5 to 19 Kilometers, Science 282, 1664-1669.

Oró, J.: 1960, Synthesis of Adenine from Ammonium Cyanide, Biochem. Biophys. Res. Comm. 2, 407-412.

Peltonen, J. P. K., He, P. and Rosenholm, J. B.: 1993, Influence of UV Irradiation on Unsaturated Fatty Acid Monolayers and Multilayer Films: X-ray Diffraction and Atomic Force Microscopy Study, Langmuir 9, 2363-2369.

Razumovsky, L. and Damodaran, S.: 1999, Surface Activity-Compressibility Relationship of Proteins at the Air-Water Interface, Langmuir 15, 1392-1399.

Schopf, J. W., Kudryavtsev, A. B., Agnesti, D. G., Wdowiak, T. J. and Czaja, A. D.: 2002, LaserRaman Imagery of Earth's Earliest Fossils, Nature 416, 73-76.

Shah, D. O.: 1970, The Origin of Membranes and Related Surface Phenomena, in C. Ponnamperuma (ed.), Chapter 7, Exobiology, North Holland, pp. 235-265.

Sicre, M.-A., Marty, J.-C. and Saliot, A.: 1990, n-Alkanes, Fatty Acid Esters, and Fatty Acid Salts in Size Fractionated Aerosols Collected over the Mediterranean Sea, J. Geophys. Res. 95, 36493657.

Simoneit, B. R. T.: 1995, Evidence for Organic Synthesis in High Temperature Aqueous Media Facts and Prognosis, Orig. Life Evol. Biosph. 25, 119-140.

Singer, S. J. and Nicholson, G. L.: 1972, The Fluid Mosaic Model of the Structure of Cell Membranes, Science 175, 720-731.

Ställberg-Stenhagen, S. and Stenhagen, E.: 1945, Phase Transitions in Condensed Monolayers of Normal Chain Carboxylic Acids, Nature 156, 239.

Tervahattu, H., Hartonen, K., Kerminen, V.-M., Kupiainen, K., Aarnio, P., Koskentalo, T., Tuck, A. F. and Vaida, V.: 2002a, New Evidence of an Organic Layer on Marine Aerosols, J. Geophys. Res. 107, 10.1029/2000JD000282.

Tervahattu, H., Juhanoja, J. and Kupiainen, K.: 2002b, Identification of an Organic Coating on Marine Aerosol Particles by TOF-SIMS, J. Geophys. Res. 107, 10.1029/2001JD001403.

Tuck, A. F.: 2002, The Role of Atmospheric Aerosols in the Origin of Life, Surv. Geophys. 23, 379-409. 